\title{
High-Frequency Stimulation of the Subthalamic Nucleus and L-3,4-Dihydroxyphenylalanine Inhibit In Vivo Serotonin Release in the Prefrontal Cortex and Hippocampus in a Rat Model of Parkinson's Disease
}

\author{
Sylvia Navailles, ${ }^{1,2}$ Abdelhamid Benazzouz, ${ }^{1,2,3}$ Bernard Bioulac, ${ }^{1,2}$ Christian Gross, ${ }^{1,2,3}$ and Philippe De Deurwaerdère ${ }^{1,2}$ \\ ${ }^{1}$ Université de Bordeaux, ${ }^{2}$ Unité Mixte de Recherche Centre National de la Recherche Scientifique 5227, and ${ }^{3}$ Centre Hospitalier Universitaire de Bordeaux, \\ 33076 Bordeaux, France
}

\begin{abstract}
High-frequency stimulation of the subthalamic nucleus (STN-HFS) and L-3,4-dihydroxyphenylalanine (L-DOPA) medication are the most used therapeutic approaches in Parkinson's disease (PD), but their beneficial motor effects are burdened by the emergence of cognitive and depressive disorders. Although a reduced serotonergic function has been linked to the psychiatric effects of antiparkinsonian treatments, biochemical evidence supporting this hypothesis is still lacking. By using a microdialysis approach in anesthetized rats, we investigated the ability of STN-HFS $(130 \mathrm{~Hz}, 30 \mu \mathrm{A}, 20 \mathrm{~min})$ and L-DOPA $(6-12 \mathrm{mg} / \mathrm{kg})$ to change extracellular levels of serotonin (5-HT) monitored simultaneously in the prefrontal cortex (PFC) and hippocampus (HIPP), two brain regions involved in the regulation of mood and cognition that receive a distinct 5-HT innervation. The results show that STN-HFS inhibited 5-HT levels in the PFC and HIPP of sham-lesioned and 6-hydroxydopamine (6-OHDA)-lesioned rats. The effect elicited by STN-HFS was blocked by the administration of the 5-HT ${ }_{1 \mathrm{~A}}$ agonist 8-hydroxy- $\mathrm{N}, \mathrm{N}$-dipropyl-2-aminotetralin. L-DOPA (6 and $12 \mathrm{mg} / \mathrm{kg}$ ) reduced 5-HT levels in the PFC and HIPP of 6-OHDA rats. STN-HFS did not further decrease 5-HT levels induced by L-DOPA, but attenuated L-DOPA-induced dopamine release in the PFC and HIPP. These neurochemical data show that STN-HFS inhibits 5-HT release by modulating serotonergic neuron activity, while the decrease in 5-HT levels induced by L-DOPA may include its direct action inside serotonergic neurons. These results support the premise that antiparkinsonian treatments reduce central serotonergic transmission, which may favor the development of nonmotor side effects in PD.
\end{abstract}

\section{Introduction}

Parkinson's disease (PD) is a neurodegenerative disorder characterized by the marked degeneration of nigral dopamine (DA) neurons. L-3,4-Dihydroxyphenylalanine (L-DOPA) usage is the most common therapy aimed at restoring central DA transmission (Hauser, 2009). High-frequency stimulation of the subthalamic nucleus (STN-HFS) is a recent surgical approach proposed to reduce L-DOPA-induced motor side effects (Fraix et al., 2000; Benabid et al., 2005). While the two different approaches are very efficient in improving the motor symptoms of the disease, their motor benefits are burdened by the occurrence of psychiatric side effects, including cognitive impairments and mood disorders (Piasecki and Jefferson, 2004; Haber and Brucker, 2009; Van Rooden et al., 2009). Compelling evidence indicates that the serotonergic system, considered as an etiologic and pathophysiological factor in PD (Zesiewicz and Hauser, 2002; Scholtissen et

Received 0ct. 9, 2009; revised Dec. 29, 2009; accepted Jan. 5, 2010.

This work was supported by grants from Centre National de la Recherche Scientifique and Bordeaux 2 University. We thank Dr. E. Bézard and Dr. M. Cador for providing technical equipment and Dr. M. Guthrie for linguistic assistance.

Correspondence should be addressed to Philippe De Deurwaerdère, Université Bordeaux 2, Unité Mixte de Recherche, Centre National de la Recherche Scientifique 5227, 146 rue Léo Saignât, 33076 Bordeaux Cedex, France. E-mail: deurwaer@u-bordeaux2.fr.

DOI:10.1523/JNEUROSCI.5031-09.2010

Copyright $\odot 2010$ the authors $\quad 0270-6474 / 10 / 302356-09 \$ 15.00 / 0$ al., 2006), plays a role in cognitive and mood disorders (Piñeyro and Blier, 1999; Bhagwagar et al., 2002). Changes in serotonergic function could participate in nonmotor side effects induced by antiparkinsonian therapies (Melamed et al., 1996).

Very few preclinical studies have focused on the effect of antiparkinsonian therapies on serotonergic parameters. Recently, it has been reported that STN-HFS inhibits the activity of serotonergic neurons in rats (Temel et al., 2007). On the other hand, the impact of L-DOPA on serotonergic function is complicated by the fact that L-DOPA enters serotonergic neurons, resulting in their terminals releasing DA as a false neurotransmitter ( $\mathrm{Ng}$ et al., 1970; Arai et al., 1995; Tanaka et al., 1999). While the few data available suggest a decrease in serotonergic function elicited by both approaches, the in vivo biochemical evidence on serotonin (5-HT) release in the DA-depleted brain is lacking.

The prefrontal cortex (PFC) and the hippocampus (HIPP) are two brain regions involved in the regulation of mood and cognition (Vertes, 2006; Drevets et al., 2008) that receive distinct serotonergic innervation from the dorsal raphe nucleus (DRN) and/or median raphe nucleus (MRN) (Molliver, 1987; Vertes, 1991). Several data indicate that the control of 5-HT release in the PFC and HIPP is different due to the distinct 5-HT projections (Kreiss and Lucki, 1994), suggesting that STN-HFS and/or L-DOPA treatments could differentially alter 5-HT release in these brain regions. 
In the present study, we investigated the effect of STN-HFS and L-DOPA on 5-HT extracellular levels monitored simultaneously using intracerebral microdialysis in the PFC and ventral HIPP of isoflurane-anesthetized rats. The influence of STN-HFS was studied in sham- and unilateral 6-hydroxydopamine (6OHDA)-lesioned rats, a rat model of PD. The 5- $\mathrm{HT}_{1 \mathrm{~A}}$ agonist 8-hydroxy- $N, N$-dipropyl-2-aminotetralin (8-OHDPAT) was used in sham-lesioned rats to determine the impact of the reduction of 5-HT cell firing on the effect of STN-HFS on 5-HT release (Sprouse and Aghajanian, 1987; Bosker et al., 1996). The influence of L-DOPA (6-12 mg/kg) was studied on 5 -HT release in the PFC and HIPP of 6-OHDA-lesioned rats. Finally, the effect of combined L-DOPA and STN-HFS on both DA and 5-HT release was studied.

\section{Materials and Methods}

Animals. Male Sprague Dawley rats (IFFA Credo) weighing 240-280 g were kept at constant room temperature $\left(21 \pm 2^{\circ} \mathrm{C}\right)$ and relative humidity (60\%) with a $12 \mathrm{~h}$ light/dark cycle (dark from 8 P.M.) and had ad libitum access to water and food. All animal use procedures conformed to European Economic Community (86-6091 EEC) and the French National Committee (décret 87/848, Ministère de l'Agriculture et de la Forêt) guidelines for the care and use of laboratory animals and were approved by the Ethical Committee of Centre National de la Recherche Scientifique, Région Aquitaine-Limousin. All efforts were made to minimize animal suffering and to reduce the number of animals used.

Drugs. 6-Hydroxydopamine hydrobromide, L-DOPA methyl ester hydrochloride, benserazide hydrochloride, desipramine hydrochloride, ( \pm )8-OHDPAT hydrobromide, and chloral hydrate were purchased from Sigma. All drug doses were calculated as the free base. All other chemicals and reagents were the purest commercially available (VWR; Sigma).

6-Hydroxydopamine injections in the medial forebrain bundle. Animals $(n=39)$ were anesthetized with chloral hydrate $(400 \mathrm{mg} / \mathrm{kg}$, i.p. $)$, placed on a stereotaxic frame, and received desipramine $(25 \mathrm{mg} / \mathrm{kg}$, i.p.) $30 \mathrm{~min}$ before 6-OHDA injection to protect noradrenergic neurons. 6-OHDA (3 $\mu \mathrm{g} / \mu \mathrm{l})$ was dissolved in saline solution containing ascorbic acid (1 mM) and injected with air pressure using a glass pipette (Mallet et al., 2006). The stereotaxic coordinates of the injection site were as follows (in $\mathrm{mm}$ ): anteroposterior $(\mathrm{AP})=-3.7$; lateral $(\mathrm{L})=+1.6$ with respect to the bregma (Paxinos and Watson, 1998). Five injections (0.5 $\mu \mathrm{l} / 1 \mathrm{~min}$ each) separated by $250 \mu \mathrm{m}$ vertical intervals along the dorsoventral (DV) extent were performed between -7 and $-8 \mathrm{~mm}$ with respect to the surface of the brain. Sham-lesioned animals $(n=27)$ received an identical volume of vehicle alone.

Implantation of microdialysis probes and stimulating electrode. Shamand 6-OHDA-lesioned rats were anesthetized by inhalation of a $3 \%$ isoflurane/air mixture in a hermetic chamber and placed on a stereotaxic frame equipped with a nose mask for constant delivery of the gas anesthesia during surgery (2\% isoflurane) and with dialysis experiments ( $1.5 \%$ isoflurane). The dorsal skull was exposed and holes were drilled to facilitate the simultaneous, ipsilateral implantation of two microdialysis probes ( $4 \mathrm{~mm}$ long) into the HIPP and PFC and the stimulating electrode in the STN on the left lesioned side. The stereotaxic coordinates used were as follows (in mm relative to bregma): $\mathrm{HIPP}: \mathrm{AP}=5.8, \mathrm{~L}=+5$, $\mathrm{DV}=-7.1$; PFC: $\mathrm{AP}=+3.2, \mathrm{~L}=+0.6, \mathrm{DV}=-3.2$; $\mathrm{STN}: \mathrm{AP}=-3.8$, $\mathrm{L}=-2.5, \mathrm{DV}=-7.5$ (Paxinos and Watson, 1998). During implantation and microdialysis experiments, body temperature was maintained at $+37^{\circ} \mathrm{C}$ with a feedback-controlled heating pad. The location of the probes was determined histologically on serial coronal sections $(60 \mu \mathrm{m})$ stained with cresyl violet, and only data obtained from rats with correctly implanted probes (Fig. 1) were included in the results; $10 \%$ of rats who underwent surgery were excluded.

Electrical stimulation of the STN. A concentric stimulating bipolar electrode (NEX-100, outer diameter $200 \mu \mathrm{m}$; Phymep) was used. Stimuli were delivered over a $20 \mathrm{~min}$ period by an isolated stimulator (NeuroLog System; Digitimer). Stimulation parameters corresponded
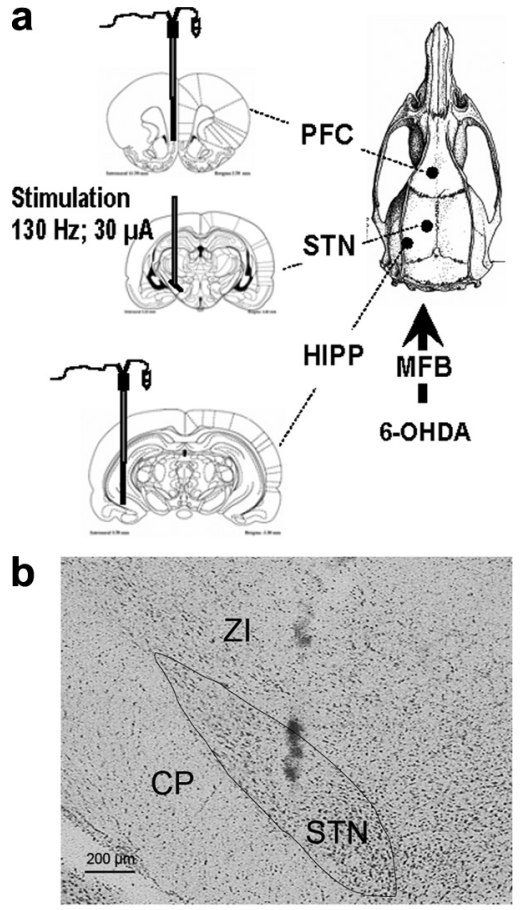

Figure 1. $\boldsymbol{a}$, Representation of the stereotaxic device for the simultaneous and ipsilateral implantation of two microdialysis probes in the PFC and the HIPP with or without the stimulation electrode in the STN. The picture on the right representing the top of the rat skull shows the stereotaxic bulk due to the simultaneous implantation of the probes. Three to four weeks earlier, rats received a unilateral injection of 6-0HDA or its vehicle into the left medial forebrain bundle (MFB). The stereotaxic plates taken from Paxinos and Watson (1998) display the probe's location in sham- and 6-OHDA-lesioned rats in the left PFC, STN, and HIPP. $\boldsymbol{b}$, Illustrative coronal section showing the histological verification of electrode location in the STN (scale bar, 200 $\mu \mathrm{m})$. CP, Cerebral peduncle; ZI, zona incerta.

to those used in clinical practice (frequency $130 \mathrm{~Hz}, 60 \mu$ s rectangular pulse width) except the intensity $(30 \mu \mathrm{A})$ which was adapted to the rat (Temel et al., 2007). Only rats shown to have the tip of the stimulating electrode in the STN were retained for the statistical analysis of the data (Fig. 1).

Microdialysis. Perfusion was performed as previously described (De Deurwaerdère et al., 2004) with minor modifications. Microdialysis probes (CMA/11, $240 \mu \mathrm{m}$ outer diameter, cuprophan; Carnegie Medicin, Phymep) were perfused at a constant flow rate of $0.5 \mu \mathrm{l} / \mathrm{min}$ by means of a microperfusion pump (CMA/100; Carnegie Medicin, Phymep) with artificial CSF containing the following (in mM): 154.1 $\mathrm{Cl}^{-}, 147 \mathrm{Na}^{+}, 2.7 \mathrm{~K}^{+}, 1 \mathrm{Mg}^{2+}$, and $1.2 \mathrm{Ca}^{2+}$, adjusted to $\mathrm{pH} 7.4$ with 2 mu sodium phosphate buffer. Dialysates were collected on ice every 20 $\mathrm{min}$. The in vitro recoveries of the probes were $\sim 20 \%$. At the end of each experiment, rat brains were removed and immediately frozen in isopentane $\left(-50^{\circ} \mathrm{C}\right)$ and stored at $-80^{\circ} \mathrm{C}$ until histological verification and postmortem analysis.

Chromatographic analysis. Dialysate samples $(10 \mu \mathrm{l})$ were immediately analyzed by reverse-phase HPLC coupled with electrochemical detection (ECD) as described previously (De Deurwaerdère et al., 2004). The mobile phase [containing the following (in mM): $70 \mathrm{NaH}_{2} \mathrm{PO}_{4}, 0.1$ EDTA, and 0.1 octylsulfonic acid plus $15 \%$ methanol, adjusted to $\mathrm{pH} 4.5$ with ortophosphoric acid] was delivered at $0.25 \mathrm{ml} / \mathrm{min}$ flow rate (Beckman pump 116) through an Equisil-BDS column $(\mathrm{C} 18,2 \times 250 \mathrm{~mm}$, particle size $5 \mu \mathrm{m}$; CIL Cluzeau). Detection of DA, 5-HT, and 5-hydroxyindoleacetic acid (5-HIAA) was performed with an amperometric cell Ag/ $\mathrm{AgCl}$ (VT-03) coupled to a programmable detector (Decade II Antec; Alpha Mos). The potential of the electrodes was set at $+500 \mathrm{mV}$. Output signals were recorded on a computer (Beckman System Gold). Under these conditions, the sensitivity values for DA, 5-HT, and 5-HIAA were $0.3,0.1$, and $5 \mathrm{pg} / 10 \mu \mathrm{l}$, respectively, with a signal/noise ratio of $3: 1$. 
Tissue concentrations of monoamines [DA, 5-HT and/or noradrenaline (NA)] in the striatum and the frontal cortex were performed by HPLC-ECD to evaluate the extent and the selectivity of the 6-OHDA lesion, as described previously (De Deurwaerdère et al., 1998). The left and right sides of the striatum and the frontal cortex were dissected at $-20^{\circ} \mathrm{C}$ and stored at $-80^{\circ} \mathrm{C}$ until their use in biochemical assays. Tissues were homogenized in $200 \mu \mathrm{l}$ of $0.1 \mathrm{~N} \mathrm{HClO}_{4}$ and centrifuged at 13,000 $\mathrm{rpm}$ for $30 \mathrm{~min}$ at $4^{\circ} \mathrm{C}$. Aliquots $(50 \mu \mathrm{l})$ of the supernatants were diluted in the mobile phase ( $1 / 4$ for the striatum and $1 / 2$ for the frontal cortex) before being injected into the HPLC column (Chromasyl C8, $150 \times 4.6$ $\mathrm{mm}, 5 \mu \mathrm{m})$ protected by a Brownlee-Newgard precolumn (RP-8, $15 \times$ $3.2 \mathrm{~mm}, 7 \mu \mathrm{m}$ ). The mobile phase, delivered at $1.2 \mathrm{ml} / \mathrm{min}$ flow rate, was as follows (in mM): $60 \mathrm{NaH}_{2} \mathrm{PO}_{4}, 0.1$ disodium EDTA, and 2 octane sulfonic acid plus 7\% methanol, adjusted to $\mathrm{pH} 3.9$ with orthophosphoric acid and filtered through a $0.22 \mathrm{~mm}$ Millipore filter. Detection of compounds was performed with a coulometric detector (Coulochem I; ESA) coupled to a conditioning cell (model 5100) and a dual-electrode analytic cell (model 5011). The potential of the electrodes was set at +350 and $-270 \mathrm{mV}$, whereas that of the conditioning cell was set at $+100 \mathrm{mV}$. Results are expressed as nanograms per milligram (ng/mg) of tissue, and each value is the mean \pm SEM.

Treatments. All treatments were given after determining a stable baseline, usually obtained $3 \mathrm{~h}$ after the insertion of the microdialysis probes. Experiments were performed in 6-OHDA- and sham-lesioned rats and started 21-28 d after the injection of 6-OHDA and its vehicle, respectively. The presence of an effective lesion of DA neurons was not checked behaviorally before dialysis experiments. The extent and the selectivity of the DA lesion were evaluated by postmortem tissue concentrations of monoamines (De Deurwaerdère et al., 1998). The effect of STN-HFS on 5-HT and 5-HIAA extracellular levels in the PFC and HIPP was assessed in sham- and 6-OHDA-lesioned rats. As there were similar effects of STN-HFS in both groups, we used sham-lesioned rats to further determine and characterize the effect of STN-HFS in the presence of the 5- $\mathrm{HT}_{1 \mathrm{~A}}$ agonist 8-OHDPAT. 8-OHDPAT is known to decrease 5-HT release (Adell et al., 1993; Casanovas and Artigas, 1996) by inhibiting 5-HT neuronal firing through the stimulation of the negative feedback control at somatodendritic 5- $\mathrm{HT}_{1 \mathrm{~A}}$ autoreceptors (Sprouse and Aghajanian, 1987). Therefore, this 5-HT compound was used to specifically address whether the decrease in 5-HT release induced by STN-HFS is related to its ability to inhibit 5-HT neuronal firing (Temel et al., 2007). 8 -OHDPAT $(0.1 \mathrm{mg} / \mathrm{kg})$ or its vehicle (sterile water) was injected subcutaneously 20 min after the end of the STN-HFS period. The administration time of 8-OHDPAT was chosen on the basis of its pharmacokinetic properties, such that it was at its pharmacodynamic maximum when the effect of STN-HFS on 5-HT release was maximal.

The effect of L-DOPA on 5-HT and 5-HIAA extracellular levels in the PFC and HIPP was assessed in DA-depleted rats. L-DOPA was administered intraperitoneally at 6 and $12 \mathrm{mg} / \mathrm{kg}$ ( $n=4$ and 5 , respectively). It was dissolved in saline and injected $20 \mathrm{~min}$ after the administration of the peripheral monoamine oxidase inhibitor benserazide $(15 \mathrm{mg} / \mathrm{kg}$, i.p.). In a last set of experiments, we combined L-DOPA (12 mg/kg) and STNHFS and studied their effect on 5-HT, 5-HIAA, and DA extracellular levels. L-DOPA was preceded by the administration of benserazide ( 15 $\mathrm{mg} / \mathrm{kg}$, i.p.) while the STN-HFS started $80 \mathrm{~min}$ later, the time at which the effect of L-DOPA on DA release was maximal.

Data and statistical analysis. 5-HT and 5-HIAA contents in each sample were expressed as the percentage of the average baseline level calculated from the three fractions preceding any treatment. Data correspond to the mean \pm SEM values of the percentage obtained in each experimental group. The overall effect of treatments corresponds to the averaged percentages of baseline for dialysates collected after the administration of treatments. DA extracellular levels stimulated by L-DOPA were expressed in $\mathrm{pg} / 10 \mu \mathrm{l}$ and corresponded to the mean \pm SEM values in each group. In postmortem analysis, tissue concentration of monoamines was expressed in $\mathrm{ng} / \mathrm{mg}$ tissue and corresponds to the mean \pm SEM values of each group.

The ability of the 6-OHDA lesion to modify 5-HT and 5-HIAA extracellular levels and monoamine tissue concentration was analyzed using a Student's $t$ test. The ability of L-DOPA to modify 5-HT and 5-HIAA
Table 1. Effect of the unilateral 6-OHDA lesion on monoamine tissue concentrations in the ipsilateral and contralateral striatum and frontal cortex

\begin{tabular}{|c|c|c|c|c|}
\hline \multirow[b]{2}{*}{ Tissue (ng/mg) } & \multicolumn{2}{|l|}{ Sham } & \multicolumn{2}{|l|}{ 6-OHDA } \\
\hline & Ipsilateral & Contralateral & Ipsilateral & Contralateral \\
\hline \multicolumn{5}{|l|}{ Striatum } \\
\hline DA & $5862 \pm 618$ & $6405 \pm 1322$ & $N D^{* * *}$ & $5252 \pm 885$ \\
\hline 5-HT & $416 \pm 55$ & $571 \pm 103$ & $499 \pm 166$ & $564.5 \pm 132$ \\
\hline \multicolumn{5}{|l|}{ Frontal cortex } \\
\hline NA & $275 \pm 50$ & $397 \pm 62$ & $215 \pm 47$ & $357 \pm 32$ \\
\hline 5-HT & $170 \pm 24$ & $226 \pm 30$ & $181 \pm 22$ & $248 \pm 52$ \\
\hline
\end{tabular}

Each value, expressed in $\mathrm{ng} / \mathrm{mg}$ of tissue, represents the mean \pm SEM of 10 and 14 rats in the sham- and 6-OHDAlesioned groups, respectively. Measurements were performed 3- 4 weeks after the unilateral injection of 6-OHDA or its vehicle (sham) in the median forebrain bundle. Rats did not receive any pharmacological treatment and/or STN-HFS. ${ }^{* * *} p<0.001$ versus the ipsilateral side of sham-lesioned rats and the contralateral side of 6-OHDAlesioned rats (Student's t test). ND, Not detectable.

Table 2. Effect of the unilateral 6-OHDA lesion on absolute basal levels of 5-HT and 5-HIAA in dialysates from the ipsilateral prefrontal cortex and hippocampus

\begin{tabular}{lcr}
\hline Tissue $(\mathrm{pg} / 10 \mu \mathrm{l})$ & \multicolumn{1}{c}{ Sham } & \multicolumn{1}{c}{6 -OHDA } \\
\hline Prefrontal cortex & & \\
5-HT & $1.39 \pm 0.10$ & $1.25 \pm 0.08$ \\
5-HIAA & $201.7 \pm 8.6$ & $216.8 \pm 11.9$ \\
Hippocampus & & \\
5-HT & $1.21 \pm 0.06$ & $1.10 \pm 0.06$ \\
5-HIAA & $233 \pm 17.4$ & $250.3 \pm 14.4$ \\
\hline
\end{tabular}

Each value, expressed in $\mathrm{pg} / 10 \mu$ l dialysates, represents the mean \pm SEM of 27 and 39 rats in the sham- and 6-OHDA-lesioned group, respectively. Data are not adjusted from probe recovery and correspond to basal extracellular levels of 5-HT and 5-HIAA before any pharmacological treatment and/or STN-HFS. Experiments were performed 3- 4 weeks after the unilateral injection of 6-OHDA or its vehicle (sham) into the medial forebrain bundle. No statistical difference between groups was observed (Student's $t$ test).

extracellular levels in 6-OHDA-lesioned rats was analyzed using a oneway ANOVA with the dose as the main factor. When significant $(p<$ 0.05 ), it was followed by a post hoc Fisher's protected least significance difference test (Fisher's PLSD) to allow for adequate multiple comparisons between groups. In the case of a two-between-factor experimental design (6-OHDA lesion and STN-HFS, STN-HFS and 8-OHDPAT in sham-lesioned rats, STN-HFS and L-DOPA in 6-OHDA-lesioned rats on 5-HT and 5-HIAA extracellular levels), implying four experimental groups, the statistical analysis was performed by a two-way ANOVA. When significant $(p<0.05)$, it was followed by the post hoc Fisher's PLSD. The influence of STN-HFS on L-DOPA-induced DA extracellular levels was analyzed using a Student's $t$ test. Finally, a one-way ANOVA was performed in each experiment to determine whether absolute 5-HT levels were homogenous across groups.

\section{Results}

\section{Biochemical assessment of the 6-OHDA lesion}

The unilateral injection of 6-OHDA into the left medial forebrain bundle suppressed tissue DA levels in the left striatum compared to the nonlesioned side (right striatum; $p<0.001$, Student's $t$ test). The values obtained in the nonlesioned side corresponded to values obtained in sham-lesioned rats (Table 1). Tissue levels of NA and 5-HT were not significantly different between the left and right sides of the striatum and frontal cortex, and the values were similar to those obtained in sham-lesioned rats [not significant (NS)]. Only data from rats with a complete lesion of DA neurons $(>99 \%$, corresponding to undetectable levels of tissue DA in the striatum) were included in the study.

\section{Effect of the 6-OHDA lesion on basal 5-HT and 5-HIAA extracellular levels in dialysates from the PFC and HIPP} All in vivo measurements were performed $120 \mathrm{~min}$ after the beginning of perfusion, by which time a steady state was achieved. Absolute basal levels of 5-HT and 5-HIAA in dialysates collected from the PFC and HIPP were not affected by the 6-OHDA lesion 
Prefrontal cortex

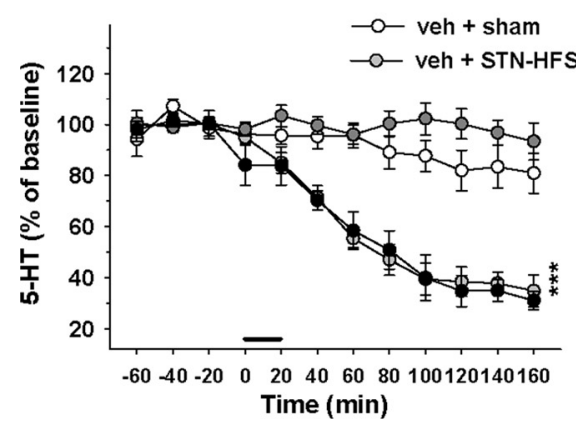

Hippocampus

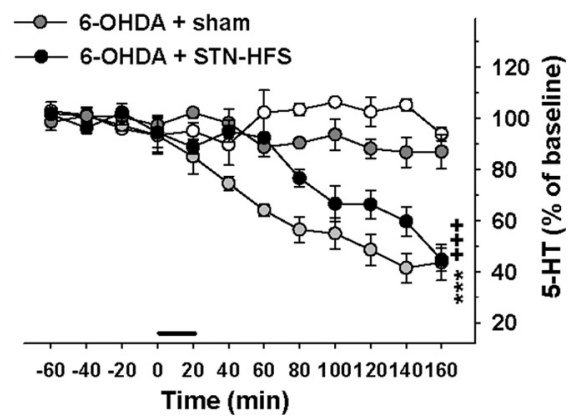

Figure 2. Effect of STN-HFS on 5-HT extracellular levels in the PFC and HIPP of sham-lesioned and 6-OHDA-lesioned rats. Dialysis experiments were performed 21-28 d after the injection of 6-OHDA or its vehicle (veh) in the median forebrain bundle. STN-HFS $(130 \mathrm{~Hz} ; 30 \mu \mathrm{A})$ or sham stimulation (sham) was applied for a 20 min period as indicated by the horizontal bar. Data represent the mean \pm SEM percentages of baseline in each sample $\left(n=4-5\right.$ rats/group) along the time course of the study. ${ }^{* * *} p<0.001$ for veh + STN-HFS group versus the veh + sham group; ${ }^{+++} p<0.001$ for the 6-OHDA + STN-HFS group versus the veh + STNHFS group (Fisher's PLSD test).

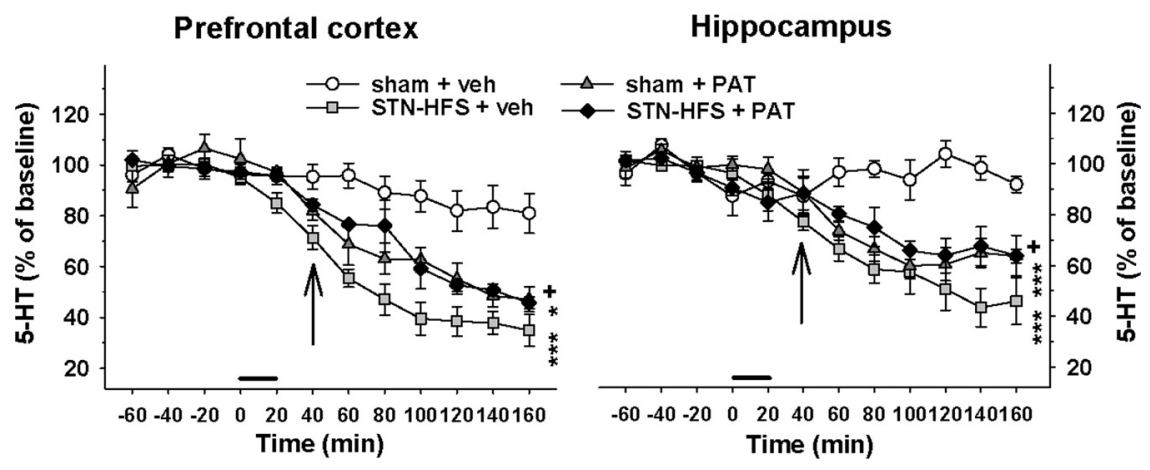

Figure 3. Influence of 8-OHDPAT on the decrease in 5-HT extracellular levels induced by STN-HFS in sham-lesioned rats. STN-HFS $(130 \mathrm{~Hz} ; 30 \mu \mathrm{A})$ or sham stimulation (sham) was applied for a 20 min period as indicated by the horizontal bar. 8-OHDPAT (PAT) or its vehicle (veh) was administered subcutaneously at $0.1 \mathrm{mg} / \mathrm{kg} 20 \mathrm{~min}$ after the end of STN-HFS or sham stimulation as indicated by the vertical arrows. Data represent the mean \pm SEM percentages of baseline. ${ }^{*} p<0.05$, ${ }^{* * *} p<0.001$ for the sham + PAT or the STN-HFS + veh groups versus the sham + veh group, ${ }^{+} p<0.05$ for the STN-HFS + PAT group versus the STN-HFS + veh group (Fisher's PLSD test).

(NS, Student's $t$ test) (Table 2). In the rest of the study, absolute levels of 5-HT in dialysates did not differ between the different experimental groups throughout the course of the study (NS, one-way ANOVA). Finally, basal extracellular levels of DA were undetectable in both brain regions of sham- and 6-OHDAlesioned rats.

\section{Effect of STN-HFS on 5-HT extracellular levels in the PFC and HIPP of sham- and 6-OHDA- lesioned rats} STN-HFS induced a significant reduction of 5-HT levels in the PFC and HIPP of both sham- and 6-OHDA-lesioned rats (oneway ANOVA, $F_{(3,15)}=32$ in the PFC and $F_{(3,15)}=48.2$ in the HIPP, $p<0.001$ ) (Fig. 2). In sham-lesioned rats, 5-HT levels progressively decreased after the beginning of STN-HFS to reach 35 and $44 \%$ of baseline at the end of the experiment (140 min after the stimulation period) in the PFC and HIPP, respectively $(p<0.001$, Fisher's PLSD test). In 6-OHDA-lesioned rats, the decrease in 5-HT extracellular levels induced by the STN-HFS in the PFC was not modified by the 6-OHDA lesion (two-way ANOVA, $F_{(1,15)}=1.7, \mathrm{NS}$ ) and followed a similar time course as in sham-lesioned rats. However, the decrease in 5-HT extracellular levels induced by STN-HFS in the HIPP was significantly delayed compared to sham-lesioned rats (two-way ANOVA,
$\left.F_{(1,15)}=19.5, p<0.001\right)$. Indeed, this effect became significant 60 min later than in sham-lesioned rats $(p<0.001$ versus the sham-6-OHDA-plus-STN-HFS group, Fisher's PLSD test). The 6-OHDA lesion did not significantly alter the effect of STN-HFS on 5-HIAA extracellular levels in both brain regions (two-way ANOVA, $F_{(1,15)}=0.02$ and 1.3 in the PFC and HIPP, respectively, NS; data not shown). STN-HFS induced a significant decrease in 5-HIAA extracellular levels only in the HIPP of both sham- and 6-OHDAlesioned rats $(p<0.001$, Fisher's PLSD test after a significant one-way ANOVA, $F_{(3,15)}=10.1, p<0.001$; data not shown).

\section{Effect of 8-OHDPAT on the inhibition} of 5-HT extracellular levels induced by STN-HFS

To determine whether the decrease in 5-HT levels induced by STN-HFS depends on serotonergic nerve activity, the effect of STN-HFS was evaluated in the presence of the $5-\mathrm{HT}_{1 \mathrm{~A}}$ agonist 8-OHDPAT in sham-lesioned rats (Fig. 3). 8-OHDPAT was administered at a dose $(0.1 \mathrm{mg} / \mathrm{kg})$ known to decrease extracellular 5-HT levels by dampening the firing rate of 5-HT neurons through the stimulation of 5- $\mathrm{HT}_{1 \mathrm{~A}}$ receptors (Casanovas et al., 2000). Accordingly, 8-OHDPAT progressively decreased 5-HT levels to $\sim 47 \%$ of baseline in the PFC $(p<0.01$, Fisher's PLSD test) and $64 \%$ of baseline in the HIPP $(p<0.001)$ at the end of the experiment $(120 \mathrm{~min}$ after 8 -OHDPAT administration). The statistical analysis revealed a significant interaction between 8-OHDPAT and STN-HFS on 5-HT extracellular levels in the PFC (two-way ANOVA, $F_{(1,13)}=21.8, p<$ $0.001)$ and the $\operatorname{HIPP}\left(F_{(1,13)}=17.8, p<0.001\right)$. In the presence of 8-OHDPAT, the decrease in 5-HT extracellular levels induced by STN-HFS was significantly less in the PFC $(p<0.05$, Fisher's PLSD test after a significant one-way ANOVA, $F_{(3,13)}=15.1, p<$ $0.001)$ and HIPP $(p<0.05$, Fisher's PLSD test after a significant one-way ANOVA, $\left.F_{(3,13)}=27.9, p<0.001\right)$. Indeed, 5-HT dialysate concentrations in STN-HFS rats in the presence of 8-OHDPAT followed the same time course of the effect with 8-OHDPAT alone.

\section{Effect of L-DOPA on 5-HT extracellular levels in the PFC and HIPP of 6-OHDA-lesioned rats}

L-DOPA at 6 and $12 \mathrm{mg} / \mathrm{kg}$ dose-dependently decreased 5-HT extracellular levels in both the PFC and HIPP of 6-OHDAlesioned rats (Fig. 4). The decrease was significant at the dose of $12 \mathrm{mg} / \mathrm{kg}$ in the PFC $(p<0.05$, Fisher's PLSD test after a significant one-way ANOVA, $\left.F_{(2,11)}=4, p<0.05\right)$ and reached a maximal effect at the end of the experiment (33\% of baseline 180 min after L-DOPA administration; $p<0.001$ compared to the administration of vehicle, Fisher's PLSD test for each point of the time course). No change of 5-HIAA extracellular levels was observed in the PFC (one-way ANOVA, $F_{(2,11)}=2.4$, NS; data not 
shown). In the HIPP, L-DOPA induced an overall decrease in 5-HT extracellular levels that reached statistical significance only for the dose of $6 \mathrm{mg} / \mathrm{kg}(p<0.01$, Fisher's PLSD test after a significant oneway ANOVA, $\left.F_{(2,11)}=8.5, p<0.01\right)$. This effect was associated with a decrease in 5 -HIAA extracellular levels at $6 \mathrm{mg} / \mathrm{kg}$ L-DOPA only $(p<0.05$, Fisher's PLSD test after a significant one-way ANOVA, $F_{(2,11)}=5.2, p<0.05$; data not shown). Nonetheless, the effect elicited by 12 $\mathrm{mg} / \mathrm{kg}$ on 5 -HT extracellular levels was biphasic. The analysis of the time course effect revealed that 5-HT extracellular levels were transiently increased $60-80 \mathrm{~min}$ after its administration $(\sim 125 \%$ of baseline; $p<0.01$ compared to the administration of vehicle, Fisher's PLSD test). Thereafter, 5-HT extracellular levels slowly decreased to reach levels observed in rats treated with $6 \mathrm{mg} / \mathrm{kg} \mathrm{L}-\mathrm{DOPA}$ at the end of the experiment $(65 \%$ of baseline; $p<0.01)$.

\section{Effect of combined STN-HFS and L-DOPA treatments on 5-HT extracellular levels in the PFC and HIPP of 6-OHDA-lesioned rats}

The influence of STN-HFS on the effect of L-DOPA $(12 \mathrm{mg} / \mathrm{kg})$ on 5 -HT extracellular levels in the PFC and HIPP is shown in Figure 5. In the PFC, the statistical analysis revealed a significant interaction between STN-HFS and L-DOPA on 5-HT extracellular levels (two-way ANOVA, $F_{(1,14)}=$ 17.2, $p<0.01$ ). Indeed, 5-HT extracellular levels monitored in rats receiving both L-DOPA and STN-HFS were not significantly different from 5-HT levels in rats receiving only L-DOPA or STN-HFS (NS, Fisher's PLSD test). The significant interaction illustrated that the inhibitory effects of both treatments are not independent factors. However, STN-HFS did not modify 5-HIAA extracellular levels induced by L-DOPA (two-way ANOVA, $F_{(1.14)}=0.05$, NS; data not shown).

STN-HFS significantly altered the effect of L-DOPA on both 5-HT and 5-HIAA extracellular levels in the HIPP (two-way ANOVA, $F_{(1,14)}=4.88, p<0.05$ and 14.1, $p<0.01$, respectively). The transient increase in 5-HT extracellular levels induced by L-DOPA was reduced once the STN-HFS started. It resulted in lower extracellular levels of 5-HT in the STN-HFS-plus-L-DOPA group compared to L-DOPA alone until the end of the experiment $(p<$ 0.01 , Fisher's PLSD test after a significant one-way ANOVA, $F_{(3,14)}=$ 3.6, $p<0.05)$. Similarly, 5-HIAA extracellular levels in the L-DOPAplus-STN-HFS group were significantly lower compared to the L-DOPA group ( $p<0.001$, Fisher's PLSD test after a significant one-way ANOVA, $F_{(3,14)}=8.7, p<0.01$; data not shown).

Effect of combined STN-HFS and L-DOPA treatments on DA extracellular levels in the PFC and HIPP of 6-OHDA-lesioned rats

Because newly synthesized DA from exogenous L-DOPA is supposed to take place inside vesicles of 5-HT terminals, DA release

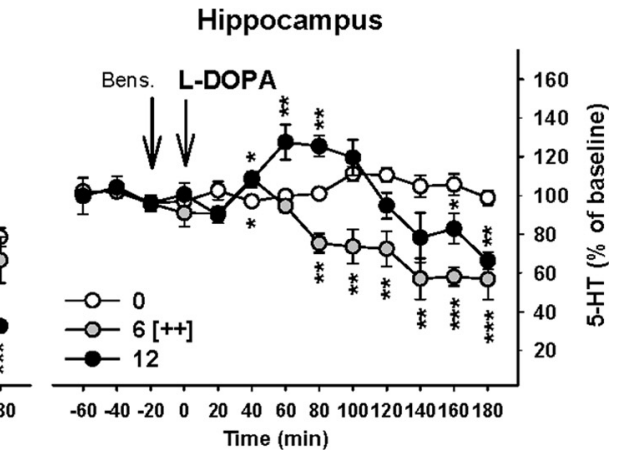

d intraperitoneally at 0,6 , and $12 \mathrm{mg} / \mathrm{kg} 20 \mathrm{~min}$ after the administration of benserazide (Bens.; $15 \mathrm{mg} / \mathrm{kg}$, i.p.) as indicated by the vertical arrows. Data represent the mean \pm SEM percentages of baseline in each sample ( $n=4-5$ rats/group) along the time course of the study. ${ }^{[+]} p<0.05,{ }^{[++]} p<0.01$ for the overall effect of the 6 or 12 groups versus the overall effect of the vehicle (0) group; ${ }^{*} p<0.05,{ }^{* *} p<0.01,{ }^{* * *} p<0.001$ for each time point of the 6 or 12 groups versus the corresponding time point of the vehicle (0) group (Fisher's PLSD test).

Prefrontal cortex

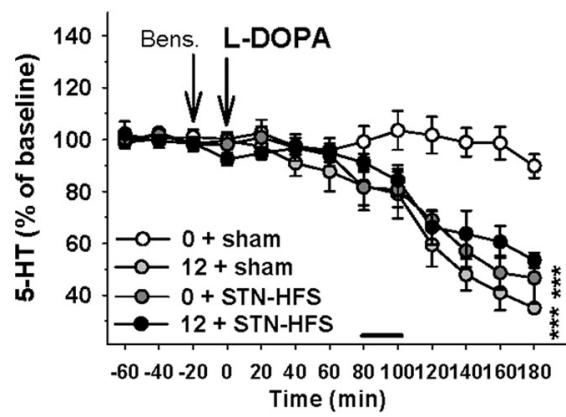

Figure 5. Influence of STN-HFS on L-DOPA-induced changes of 5-HT extracellular levels in the PFC and HIPP of 6-OHDA-lesioned EM percentages of baseline in each sample ( $n=4-6$ rats/group) along the time course of the study. ${ }^{* * *} p<0.001$ for the $12+$ sham or the $0+$ STN-HFS groups versus the $0+$ sham group; ${ }^{++} p<0.01$ for the $12+$ STN-HFS group versus the $12+$ sham group (Fisher's PLSD test). is also an index of 5-HT neuronal activity. We therefore assessed the influence of STN-HFS on the effect of L-DOPA $(12 \mathrm{mg} / \mathrm{kg})$ on DA extracellular levels in the PFC and HIPP (Fig. 6). L-DOPA per se increased DA levels in the PFC. This effect peaked at $\sim 8 \mathrm{pg} / 10$ $\mu l 100$ min after its administration and rapidly decreased to $\sim 3$ $\mathrm{pg} / 10 \mu \mathrm{l}$ at the end of the experiment. The increase in DA extracellular levels elicited by L-DOPA was significantly reduced almost by half by STN-HFS ( $p<0.01$, Student's $t$ test).

L-DOPA per se induced a significant increase in DA levels in the HIPP as well. This effect reached a plateau at $\sim 6 \mathrm{pg} / 10 \mu \mathrm{l} 60$ min after L-DOPA administration and slowly decreased to $\sim 4$ $\mathrm{pg} / 10 \mu \mathrm{l}$ at the end of the experiment (180 min after L-DOPA administration). STN-HFS significantly reduced the increase in DA extracellular levels induced by L-DOPA ( $p<0.01$, Student's $t$ test). Indeed, once STN-HFS was applied (80 min after L-DOPA administration), DA levels induced by L-DOPA rapidly decreased from $5 \mathrm{pg} / 10 \mu \mathrm{l}$ to $3 \mathrm{pg} / 10 \mu \mathrm{l}$ and remained steady until the end of the experiment.

\section{Discussion}

The present study provides the first in vivo biochemical evidence that both STN-HFS and L-DOPA inhibit 5-HT release in the PFC and HIPP of hemiparkinsonian rats. The inhibitory effect of 
Prefrontal cortex

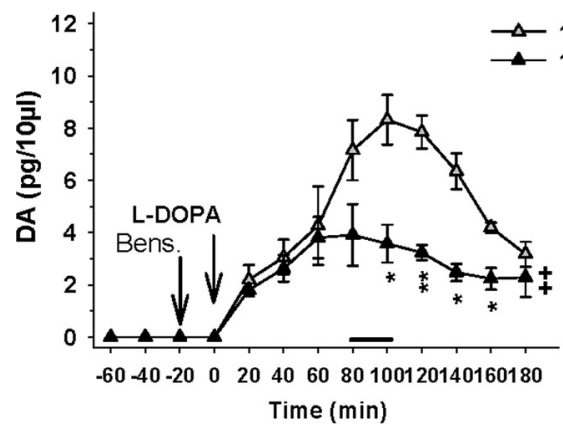

Hippocampus

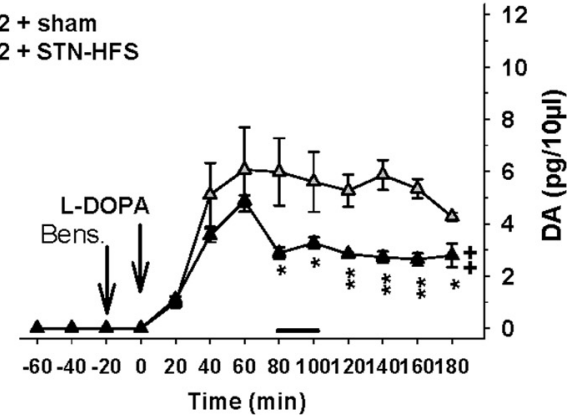

Figure 6. Influence of STN-HFS on L-DOPA-induced changes of DA extracellular levels in the PFC and HIPP of 6-OHDA-lesioned rats. STN-HFS $(130 \mathrm{~Hz} ; 30 \mu \mathrm{A})$ or sham stimulation (sham) was applied for a 20 min period as indicated by the horizontal bar and started $80 \mathrm{~min}$ after the intraperitoneal administration of L-DOPA at $12 \mathrm{mg} / \mathrm{kg}$. L-DOPA (12) was preceded $20 \mathrm{~min}$ before by the administration of benserazide (Bens.; $15 \mathrm{mg} / \mathrm{kg}$, i.p.) as indicated by the vertical bars. Absolute DA levels are expressed in $\mathrm{pg} / 10 \mu$ l of dialysate. ${ }^{++} p<0.05$ for the overall effect of the $12+$ STN-HFS group versus the overall effect of the $12+$ sham group; ${ }^{*} p<0.05,{ }^{* *} p<0.01$ for each time point of the $12+$ STN-HFS group versus the corresponding time point of the $12+$ sham group (Student's t test).

STN-HFS occurs likely via an action on 5-HT neuronal activity, whereas the inhibitory effect induced by L-DOPA may include its ability to enter 5-HT terminals. STN-HFS attenuates the ability of L-DOPA to increase DA release in both the PFC and HIPP without affecting further the decrease in 5-HT extracellular levels, a pattern of effect that may participate in the therapeutic superiority of the combined treatments in PD.

\section{Significance and validity of the 5-HT signal}

The 5-HT signal in dialysates likely corresponded to extracellular 5-HT from 5-HT terminals. Basal extracellular levels of 5-HT and 5-HIAA, detected simultaneously in the HIPP and PFC, corresponded to those previously reported (Kreiss and Lucki, 1994; Romero and Artigas, 1997). Furthermore, 5-HT extracellular levels were significantly reduced in both brain regions by 8 -OHDPAT, a 5-HT $1 \mathrm{~A}$ agonist known to reduce both 5-HT neuronal firing (Sprouse and Aghajanian, 1987; Bosker et al., 1996) and 5-HT release at nerve terminals (Sharp et al., 1989; Adell et al., 1993; Casanovas and Artigas, 1996).

\section{STN-HFS inhibits 5-HT release: role of 5-HT} neuronal activity

We show that STN-HFS inhibits 5-HT release in the HIPP and PFC in both sham- and DA-depleted rats. Our data agree with the recent study by Temel et al. (2007) showing that STN-HFS inhibits 5-HT neuron activity of the DRN similarly in shamand DA-depleted rats, an effect associated with the emergence of depressive-like symptoms in rats. Previous clinical data suggested that the ability of HFS to induce depressive symptoms in patients was related to a putative placement of the electrode in the substantia nigra pars reticulata (SNr) (Bejjani et al., 1999). In our conditions however, the direct participation of the $\mathrm{SNr}$ is unlikely because the electrode was located in the medial STN at least $1 \mathrm{~mm}$ rostral from the SNr, and the HFS was confined to the STN as currents were delivered at low intensity. The decrease in 5-HT extracellular levels induced by STN-HFS could rather be related to the inhibition of 5-HT neuronal firing at the level of the DRN and/or MRN. In line with this hypothesis, STN-HFS combined with 8-OHDPAT did not result in the summation of their inhibitory effects on 5-HT release in the PFC and HIPP, suggesting that the effect of STN-HFS is suppressed when 5-HT neuronal firing is inhibited by 8 -OHDPAT. The extracellular levels of 5-HT mea-

sured in these conditions were above the limit of detection, ruling out a putative ceiling effect related to the sensitivity of our analysis. Although the ability of 8-OHDPAT to partly reverse the stronger inhibitory effect of STN-HFS on 5-HT release could involve a depolarization blockade on 5-HT neurons induced by STN-HFS, the available electrophysiological data showing a persisting activity of 5-HT neurons after STN-HFS dampens this hypothesis (Temel et al., 2007). Additional data are warranted to determine the precise nature of the depressed action of HFS-STN on 5-HT neuron excitability.

The decrease in 5-HT release induced by STN-HFS was greater and appeared faster in the PFC compared to the HIPP of sham-depleted rats. This difference was amplified in DA-depleted rats. Although we do not have a clear explanation for these findings, such differences might be related to the different nature of 5-HT fibers innervating the HIPP and PFC. The PFC receives predominantly 5 -HT fibers from the $\mathrm{DRN}$, while the HIPP receives 5-HT fibers from DRN and MRN (Molliver, 1987; Vertes, 1991). These two 5-HT nuclei are functionally distinct and subject to different regulatory influences (Kreiss and Lucki, 1994; Invernizzi et al., 1997; Hervás et al., 1998).

\section{Effect of 6-OHDA lesion on basal 5-HT release}

DA lesion did not significantly affect basal extracellular levels of 5-HT and 5-HIAA in either region. Consistently, the destruction of DA neurons, characterized here by the suppression of tissue concentration of DA in the striatum of the lesioned side, did not affect tissue concentration of 5-HT. These results agree with previous studies reporting unchanged 5-HT tissue levels following 6-OHDA lesion (Iwamoto et al., 1976; Breese et al., 1984; Erinoff and Snodgrass, 1986). Changes of 5-HT system activity after DA lesion have been reported, however, but the data are controversial. Some studies have shown an overall hyperactivity of the 5-HT system (Commins et al., 1989; Zhou et al., 1991) with an increased activity of DRN and MRN 5-HT neurons (Temel et al., 2007; Kaya et al., 2008; Wang et al., 2009), while other studies have reported a significant reduction in 5-HT function (Takeuchi et al., 1991) with a decreased activity of DRN 5-HT neurons (Guiard et al., 2008). It is interesting to note that modifications of basal 5-HT release in the striatum of 1-methyl-4-phenyl-1,2,3,6tetrahydropyridine-treated monkeys depend on the functional territories considered (Boulet et al., 2008). These modifications might be important in territories normally enriched with DA terminals, such as the striatum, whereas changes in 5-HT extracellular levels in regions less innervated by DA fibers, such as the HIPP or PFC, would be minimal.

\section{L-DOPA inhibits 5-HT release in the HIPP and PFC of 6-OHDA-lesioned rats}

We report for the first time that the acute administration of L-DOPA dose-dependently inhibits 5-HT extracellular levels in the PFC and HIPP of hemiparkinsonian rats. Earlier studies have reported that high doses of L-DOPA decreased 5-HT tissue levels in the brain (Bartholini et al., 1968; Uretsky and Schoenfeld, 1971). At variance with the effect described after STN-HFS, the HIPP displayed a higher sensitivity to L-DOPA-induced changes 
of 5-HT and 5-HIAA extracellular levels compared to the PFC. The distinct response was also revealed by the biphasic effect on 5-HT extracellular levels obtained at the dose of $12 \mathrm{mg} / \mathrm{kg}$ in the HIPP only. Although the mechanism involved in this biphasic effect remains to be determined, an excitatory effect of focal application of L-DOPA on 5-HT extracellular levels has been previously reported in the rat substantia nigra (Biggs and Starr, 1997). Thus, our results support the idea that antiparkinsonian treatments tend to inhibit central 5-HT function but they suggest that the mechanisms underlying the inhibition of 5-HT release induced by L-DOPA and STN-HFS are different.

\section{L-DOPA and STN-HFS inhibit 5-HT release via distinct mechanisms}

The combination of STN-HFS and L-DOPA did not result in the summation of their inhibitory effects on 5-HT release in the HIPP and PFC. This finding indicates that both treatments converge on mechanisms controlling 5-HT release, and the results showing that STN-HFS did shunt the transient increase in HIPP 5-HT release induced by L-DOPA, together with those obtained on DA release, suggest that the pathways are different. DA released from 5-HT terminals may be another index of 5-HT neuronal activity in 6-OHDA rats (Tanaka et al., 1999; Carta et al., 2008; Navailles et al., 2010), because the decarboxylation of L-DOPA into DA inside 5-HT terminal leads DA to substitute 5-HT in vesicles (Ng et al., 1970; Arai et al., 1995). We found that $12 \mathrm{mg} / \mathrm{kg}$ L-DOPA strongly enhanced DA release in both the PFC and HIPP, an effect markedly reduced by STN-HFS. In line with the higher sensitivity of STN-HFS to inhibit 5-HT release in the PFC compared to the HIPP, the attenuation of L-DOPAinduced DA release by STN-HFS was more pronounced in the PFC. The inhibitory effect of STN-HFS on DA release could be related to its inhibitory action on 5-HT neuronal activity, because L-DOPA-induced DA release from striatal 5-HT terminals is sensitive to 8 -OHDPAT, presumably through a reduction of 5-HT firing rate (Kannari et al., 2001; Carta et al., 2007). Recently, it has been shown that STN-HFS prolonged the increase in DA levels induced by L-DOPA in the striatum without affecting the magnitude of its effect (Lacombe et al., 2007). Such a discrepancy might be related to the use of a higher dose of L-DOPA $(50 \mathrm{mg} / \mathrm{kg})$ in partially DA-depleted rats, a condition in which DA reuptake sites on remaining DA terminals may still regulate DA extracellular levels in the striatum (Abercrombie et al., 1990).

Altogether, our data suggest that STN-HFS and L-DOPA differentially inhibit 5-HT release involving the inhibition of 5-HT neuronal activity and the substitution of 5-HT by newly synthesized DA inside vesicles of exocytosis, respectively. In any case, the combined treatments do not potentiate the decrease in 5-HT release elicited by each treatment alone in both regions.

\section{STN-HFS and L-DOPA in the treatment of PD}

The ability of STN-HFS or L-DOPA to lower 5-HT extracellular levels may participate in the emergence of depressive symptoms (Melamed et al., 1996; Temel et al., 2007). STN-HFS is often combined with L-DOPA in the treatment of PD (Moro et al., 1999; Fraix et al., 2000). Although STN-HFS quickened the decrease in 5-HT extracellular levels induced by L-DOPA in the HIPP, it is noteworthy that the combined treatments did not potentiate the decrease in 5-HT release in any brain region. This suggests that such a therapeutic strategy may not potentiate the risk of nonmotor side effects associated with impaired
5-HT function, such as cognitive and depressive-like disorders (Smith et al., 1997; Bhagwagar et al., 2002). A predisposition to these side effects after long-term medication could be dependent on the degeneration of 5-HT and NE neurons that has been reported in PD (Melamed et al., 1996; Dauer and Przedborski, 2003; Rommelfanger and Weinshenker, 2007; Kish et al., 2008; Taylor et al., 2009).

Our study highlights the large impact of L-DOPA in the brain since L-DOPA, at therapeutic doses, dramatically increases DA release in brain regions other than the striatum. PFC and HIPP express DA receptors (Seeman, 1980) and are involved in the regulation of mood and cognition (Nieoullon, 2002). An excessive DA transmission induced by L-DOPA in these brain regions could participate in the emergence of motor and nonmotor side effects in PD. The combination of STN-HFS and L-DOPA might have multiple motor and nonmotor therapeutic benefits. Indeed, the ability of STN-HFS to stabilize DA concentrations in the PFC and HIPP (present study) or in the striatum (Lacombe et al., 2007) may dampen L-DOPA-related motor fluctuations (Nimura et al., 2005; Lundblad et al., 2009) and reduce L-DOPA-induced cognitive side effects such as pathological gambling or psychosis (Nieoullon, 2002; Siri et al., 2009).

In conclusion, these data show that STN-HFS and L-DOPA by themselves decrease 5-HT release in the PFC and HIPP in a rat model of PD. This effect may participate in the emergence of cognitive and depressive disorders after short- and long-term treatment in PD (Zesiewicz and Hauser, 2002; Scholtissen et al., 2006). Finally, we provide evidence that the combined approaches, while not aggravating the decrease in 5-HT release, could limit side effects associated with excessive DA transmission in the brain.

\section{References}

Abercrombie ED, Bonatz AE, Zigmond MJ (1990) Effects of L-dopa on extracellular dopamine in striatum of normal and 6-hydroxydopaminetreated rats. Brain Res 525:36-44.

Adell A, Carceller A, Artigas F (1993) In vivo brain dialysis study of the somatodendritic release of serotonin in the Raphe nuclei of the rat: effects of 8-hydroxy-2-(di-n-propylamino)tetralin. J Neurochem 60:1673-1681.

Arai R, Karasawa N, Geffard M, Nagatsu I (1995) L-DOPA is converted to dopamine in serotonergic fibers of the striatum of the rat: a doublelabeling immunofluorescence study. Neurosci Lett 195:195-198.

Bartholini G, Da Prada M, Pletscher A (1968) Decrease of cerebral 5-hydroxytryptamine by 3,4-dihydroxyphenylalanine after inhibition of extracerebral decarboxylase. J Pharm Pharmacol 20:228-229.

Bejjani BP, Damier P, Arnulf I, Thivard L, Bonnet AM, Dormont D, Cornu P, Pidoux B, Samson Y, Agid Y (1999) Transient acute depression induced by high-frequency deep-brain stimulation. N Engl J Med 340:1476-1480.

Benabid AL, Chabardes S, Seigneuret E, Pollak P, Fraix V, Krack P, Lebas JF, Grand S, Piallat B (2005) Functional neurosurgery: past, present, and future. Clin Neurosurg 52:265-270.

Bhagwagar Z, Whale R, Cowen PJ (2002) State and trait abnormalities in serotonin function in major depression. Br J Psychiatry 180:24-28.

Biggs CS, Starr MS (1997) Dopamine and glutamate control each other's release in the basal ganglia: a microdialysis study of the entopeduncular nucleus and substantia nigra. Neurosci Biobehav Rev 21:497-504.

Bosker FJ, de Winter TY, Klompmakers AA, Westenberg HG (1996) Flesinoxan dose-dependently reduces extracellular 5-hydroxytryptamine (5-HT) in rat median raphe and dorsal hippocampus through activation of 5-HT1A receptors. J Neurochem 66:2546-2555.

Boulet S, Mounayar S, Poupard A, Bertrand A, Jan C, Pessiglione M, Hirsch EC, Feuerstein C, François C, Féger J, Savasta M, Tremblay L (2008) Behavioral recovery in MPTP-treated monkeys: neurochemical mechanisms studied by intrastriatal microdialysis. J Neurosci 28:9575-9584.

Breese GR, Baumeister AA, McCown TJ, Emerick SG, Frye GD, Crotty K, Mueller RA (1984) Behavioral differences between neonatal and adult 6-hydroxydopamine-treated rats to dopamine agonists: relevance to neu- 
rological symptoms in clinical syndromes with reduced brain dopamine. J Pharmacol Exp Ther 231:343-354.

Carta M, Carlsson T, Kirik D, Björklund A (2007) Dopamine released from 5-HT terminals is the cause of L-DOPA-induced dyskinesia in parkinsonian rats. Brain 130:1819-1833.

Carta M, Carlsson T, Muñoz A, Kirik D, Björklund A (2008) Serotonindopamine interaction in the induction and maintenance of L-DOPAinduced dyskinesias. Prog Brain Res 172:465-478.

Casanovas JM, Artigas F (1996) Differential effects of ipsapirone on 5-hydroxytryptamine release in the dorsal and median raphe neuronal pathways. J Neurochem 67:1945-1952.

Casanovas JM, Berton O, Celada P, Artigas F (2000) In vivo actions of the selective 5 -HT1A receptor agonist BAY $\times 3702$ on serotonergic cell firing and release. Naunyn Schmiedebergs Arch Pharmacol 362:248-254.

Commins DL, Shaughnessy RA, Axt KJ, Vosmer G, Seiden LS (1989) Variability among brain regions in the specificity of 6-hydroxydopamine (6OHDA)-induced lesions. J Neural Transm 77:197-210.

Dauer W, Przedborski S (2003) Parkinson's disease: mechanisms and models. Neuron 39:889-909.

De Deurwaerdère P, Stinus L, Spampinato U (1998) Opposite change of in vivo dopamine release in the rat nucleus accumbens and striatum that follows electrical stimulation of dorsal raphe nucleus: role of $5-\mathrm{HT}_{3}$ receptors. J Neurosci 18:6528-6538.

De Deurwaerdère P, Navailles S, Berg KA, Clarke WP, Spampinato U (2004) Constitutive activity of the serotonin $2 \mathrm{C}$ receptor inhibits in vivo dopamine release in the rat striatum and nucleus accumbens. J Neurosci 24:3235-3241.

Drevets WC, Price JL, Furey ML (2008) Brain structural and functional abnormalities in mood disorders: implications for neurocircuitry models of depression. Brain Struct Funct 213:93-118.

Erinoff L, Snodgrass SR (1986) Effects of adult or neonatal treatment with 6-hydroxydopamine or 5,7-dihydroxytryptamine on locomotor activity, monoamine levels, and response to caffeine. Pharmacol Biochem Behav 24:1039-1045.

Fraix V, Pollak P, Van Blercom N, Xie J, Krack P, Koudsie A, Benabid AL (2000) Effect of subthalamic nucleus stimulation on levodopa-induced dyskinesia in Parkinson's disease. Neurology 55:1921-1923.

Guiard BP, El Mansari M, Merali Z, Blier P (2008) Functional interactions between dopamine, serotonin and norepinephrine neurons: an in-vivo electrophysiological study in rats with monoaminergic lesions. Int J Neuropsychopharmacol 11:625-639.

Haber SN, Brucker JL (2009) Cognitive and limbic circuits that are affected by deep brain stimulation. Front Biosci 14:1823-1834.

Hauser RA (2009) Levodopa: past, present, and future. Eur Neurol 62:1-8.

Hervás I, Bel N, Fernández AG, Palacios JM, Artigas F (1998) In vivo control of 5-hydroxytryptamine release by terminal autoreceptors in rat brain areas differentially innervated by the dorsal and median raphe nuclei. Naunyn Schmiedebergs Arch Pharmacol 358:315-322.

Invernizzi R, Velasco C, Bramante M, Longo A, Samanin R (1997) Effect of 5-HT1A receptor antagonists on citalopram-induced increase in extracellular serotonin in the frontal cortex, striatum and dorsal hippocampus. Neuropharmacology 36:467-473.

Iwamoto ET, Loh HH, Way EL (1976) Circling behavior in rats with 6-hydroxydopamine or electrolytic nigral lesions. Eur J Pharmacol 37:339-356.

Kannari K, Yamato H, Shen H, Tomiyama M, Suda T, Matsunaga M (2001) Activation of 5-HT(1A) but not 5-HT(1B) receptors attenuates an increase in extracellular dopamine derived from exogenously administered L-DOPA in the striatum with nigrostriatal denervation. J Neurochem 76:1346-1353.

Kaya AH, Vlamings R, Tan S, Lim LW, Magill PJ, Steinbusch HW, VisserVandewalle V, Sharp T, Temel Y (2008) Increased electrical and metabolic activity in the dorsal raphe nucleus of parkinsonian rats. Brain Res 1221:93-97.

Kish SJ, Tong J, Hornykiewicz O, Rajput A, Chang LJ, Guttman M, Furukawa Y (2008) Preferential loss of serotonin markers in caudate versus putamen in Parkinson's disease. Brain 131:120-131.

Kreiss DS, Lucki I (1994) Differential regulation of serotonin (5-HT) release in the striatum and hippocampus by 5-HT1A autoreceptors of the dorsal and median raphe nuclei. J Pharmacol Exp Ther 269:1268-1279.
Lacombe E, Carcenac C, Boulet S, Feuerstein C, Bertrand A, Poupard A, Savasta M (2007) High-frequency stimulation of the subthalamic nucleus prolongs the increase in striatal dopamine induced by acute L-3,4dihydroxyphenylalanine in dopaminergic denervated rats. Eur J Neurosci 26:1670-1680.

Lundblad M, af Bjerkén S, Cenci MA, Pomerleau F, Gerhardt GA, Strömberg I (2009) Chronic intermittent L-DOPA treatment induces changes in dopamine release. J Neurochem 108:998-1008.

Mallet N, Ballion B, Le Moine C, Gonon F (2006) Cortical inputs and GABA interneurons imbalance projection neurons in the striatum of parkinsonian rats. J Neurosci 26:3875-3884.

Melamed E, Zoldan J, Friedberg G, Ziv I, Weizmann A (1996) Involvement of serotonin in clinical features of Parkinson's disease and complications of L-DOPA therapy. Adv Neurol 69:545-550.

Molliver ME (1987) Serotonergic neuronal systems: what their anatomic organization tells us about function. J Clin Psychopharmacol 7: $3 \mathrm{~S}-23 \mathrm{~S}$.

Moro E, Scerrati M, Romito LM, Roselli R, Tonali P, Albanese A (1999) Chronic subthalamic nucleus stimulation reduces medication requirements in Parkinson's disease. Neurology 53:85-90.

Navailles S, Bioulac B, Gross C, De Deurwaerdère P (2010) Serotonergic neurons mediate ectopic release of dopamine induced by L-DOPA in a rat model of Parkinson's disease. Neurobiol Dis. Advance online publication. Retrieved January 29, 2010. doi:10.1016/j.nbd.2010.01.012.

Ng KY, Chase TN, Colburn RW, Kopin IJ (1970) L-Dopa-induced release of cerebral monoamines. Science 170:76-77.

Nieoullon A (2002) Dopamine and the regulation of cognition and attention. Prog Neurobiol 67:53-83.

Nimura T, Yamaguchi K, Ando T, Shibuya S, Oikawa T, Nakagawa A, Shirane R, Itoh M, Tominaga T (2005) Attenuation of fluctuating striatal synaptic dopamine levels in patients with Parkinson disease in response to subthalamic nucleus stimulation: a positron emission tomography study. J Neurosurg 103:968-973.

Paxinos G, Watson C (1998) The rat brain in stereotaxic coordinates. New York: Academic.

Piasecki SD, Jefferson JW (2004) Psychiatric complications of deep brain stimulation for Parkinson's disease. J Clin Psychiatry 65:845-849.

Piñeyro G, Blier P (1999) Autoregulation of serotonin neurons: role in antidepressant drug action. Pharmacol Rev 51:533-591.

Romero L, Artigas F (1997) Preferential potentiation of the effects of serotonin uptake inhibitors by $5-\mathrm{HT} 1 \mathrm{~A}$ receptor antagonists in the dorsal raphe pathway: role of somatodendritic autoreceptors. J Neurochem 68:2593-2603.

Rommelfanger KS, Weinshenker D (2007) Norepinephrine: the redheaded stepchild of Parkinson's disease. Biochem Pharmacol 74:177-190.

Scholtissen B, Verhey FR, Adam JJ, Weber W, Leentjens AF (2006) Challenging the serotonergic system in Parkinson disease patients: effects on cognition, mood, and motor performance. Clin Neuropharmacol 29:276-285.

Seeman P (1980) Brain dopamine receptors. Pharmacol Rev 32:229-313.

Sharp T, Bramwell SR, Hjorth S, Grahame-Smith DG (1989) Pharmacological characterization of 8 -OH-DPAT-induced inhibition of rat hippocampal 5-HT release in vivo as measured by microdialysis. $\mathrm{Br} \mathrm{J}$ Pharmacol 98:989-997.

Siri C, Cilia R, De Gaspari D, Canesi M, Meucci N, Zecchinelli AL, Pezzoli G, Antonini A (2009) Cognitive status of patients with Parkinson's disease and pathological gambling. J Neurol. Advance online publication. Retrieved January 20, 2010. doi:10.1007/s00415-009-5301-5.

Smith KA, Fairburn CG, Cowen PJ (1997) Relapse of depression after rapid depletion of tryptophan. Lancet 349:915-919.

Sprouse JS, Aghajanian GK (1987) Electrophysiological responses of serotoninergic dorsal raphe neurons to 5-HT1A and 5-HT1B agonists. Synapse 1:3-9.

Takeuchi Y, Sawada T, Blunt S, Jenner P, Marsden CD (1991) Effects of 6-hydroxydopamine lesions of the nigrostriatal pathway on striatal serotonin innervation in adult rats. Brain Res 562:301-305.

Tanaka H, Kannari K, Maeda T, Tomiyama M, Suda T, Matsunaga M (1999) Role of serotonergic neurons in L-DOPA-derived extracellular dopamine in the striatum of 6-OHDA-lesioned rats. Neuroreport 10:631-634. 
Taylor TN, Caudle WM, Shepherd KR, Noorian A, Jackson CR, Iuvone PM, Weinshenker D, Greene J, Miller GW (2009) Nonmotor symptoms of Parkinson's disease revealed in an animal model with reduced monoamine storage capacity. J Neurosci 29:8103-8113.

Temel Y, Boothman LJ, Blokland A, Magill PJ, Steinbusch HW, VisserVandewalle V, Sharp T (2007) Inhibition of 5-HT neuron activity and induction of depressive-like behavior by high-frequency stimulation of the subthalamic nucleus. Proc Natl Acad Sci U S A 104: 17087-17092.

Uretsky NJ, Schoenfeld RI (1971) Effect of L-dopa on the locomotor activity of rats pretreated with 6-hydroxydopamine. Nat New Biol 234:157-159.

Van Rooden SM, Visser M, Verbaan D, Marinus J, van Hilten JJ (2009) Patterns of motor and non-motor features in Parkinson's disease. J Neurol Neurosurg Psychiatry 80:846-850.
Vertes RP (1991) A PHA-L analysis of ascending projections of the dorsal raphe nucleus in the rat. J Comp Neurol 313:643-668.

Vertes RP (2006) Interactions among the medial prefrontal cortex, hippocampus and midline thalamus in emotional and cognitive processing in the rat. Neuroscience 142:1-20.

Wang S, Zhang QJ, Liu J, Wu ZH, Wang T, Gui ZH, Chen L, Wang Y (2009) Unilateral lesion of the nigrostriatal pathway induces an increase of neuronal firing of the midbrain raphe nuclei 5-HT neurons and a decrease of their response to $5-\mathrm{HT}(1 \mathrm{~A})$ receptor stimulation in the rat. Neuroscience 159:850-861.

Zesiewicz TA, Hauser RA (2002) Depression in Parkinson's disease. Curr Psychiatry Rep 4:69-73.

Zhou FC, Bledsoe S, Murphy J (1991) Serotonergic sprouting is induced by dopamine-lesion in substantia nigra of adult rat brain. Brain Res 556: $108-116$. 